\title{
BMJ Open Assessing the impact on chronic disease of incorporating the societal cost of greenhouse gases into the price of food: an econometric and comparative risk assessment modelling study
}

\author{
Adam D M Briggs, ${ }^{1}$ Ariane Kehlbacher, ${ }^{2}$ Richard Tiffin, ${ }^{2}$ Tara Garnett, ${ }^{3}$ \\ Mike Rayner, ${ }^{1}$ Peter Scarborough ${ }^{1}$
}

To cite: Briggs ADM, Kehlbacher A, Tiffin R, et al. Assessing the impact on chronic disease of incorporating the societal cost of greenhouse gases into the price of food: an econometric and comparative risk assessment modelling study. BMJ Open 2013;3: e003543. doi:10.1136/ bmjopen-2013-003543

- Prepublication history and additional material for this paper is available online. To view these files please visit the journal online (http://dx.doi.org/10.1136/ bmjopen-2013-003543).

Received 4 July 2013

Revised 5 September 2013

Accepted 24 September 2013

CrossMark

For numbered affiliations see end of article.

Correspondence to Dr Adam Briggs; adam. briggs@dph.ox.ac.uk

\section{ABSTRACT}

Objectives: To model the impact on chronic disease of a tax on UK food and drink that internalises the wider costs to society of greenhouse gas (GHG) emissions and to estimate the potential revenue.

Design: An econometric and comparative risk assessment modelling study.

Setting: The UK.

Participants: The UK adult population.

Interventions: Two tax scenarios are modelled: $(\mathrm{A}) \mathrm{a}$ tax of £2.72/tonne carbon dioxide equivalents $\left(\mathrm{tCO}_{2} \mathrm{e}\right) /$ $100 \mathrm{~g}$ product applied to all food and drink groups with above average $\mathrm{GHG}$ emissions. (B) As with scenario $(A)$ but food groups with emissions below average are subsidised to create a tax neutral scenario. Outcome measures: Primary outcomes are change in UK population mortality from chronic diseases following the implementation of each taxation strategy, the change in the UK GHG emissions and the predicted revenue. Secondary outcomes are the changes to the micronutrient composition of the UK diet.

Results: Scenario (A) results in 7770 (95\% credible intervals 7150 to 8390 ) deaths averted and a reduction in GHG emissions of 18683 (14 665to 22 889) $\mathrm{ktCO}{ }_{2} \mathrm{e} /$ year. Estimated annual revenue is $£ 2.02$ ( $£ 1.98$ to £2.06) billion. Scenario (B) results in 2685 (1966 to 3402) extra deaths and a reduction in $\mathrm{GHG}$ emissions of 15228 (11 245to 19 492) ktCO $\mathrm{e} / \mathrm{year}$.

Conclusions: Incorporating the societal cost of GHG into the price of foods could save 7770 lives in the UK each year, reduce food-related GHG emissions and generate substantial tax revenue. The revenue neutral scenario (B) demonstrates that sustainability and health goals are not always aligned. Future work should focus on investigating the health impact by population subgroup and on designing fiscal strategies to promote both sustainable and healthy diets.

\section{INTRODUCTION}

Climate change has been described as the biggest global health threat of the 21st century with rising global temperatures

\section{ARTICLE SUMMARY}

Strengths and limitations of the study

- This study uses the best currently available datasets to estimate the effects of a taxation strategy on both the taxed product, as well as on substituting and complementing products.

- The data on UK greenhouse gas emissions for different food groups are not complete meaning that for some foods, levels of emissions were estimated from related food groups or constituent ingredients.

- Owing to limitations of the economic data, this study is not able to estimate the health impact by different subgroups of society, such as socioeconomic group.

projected to alter disease patterns, increase food and water insecurity and lead to extreme climatic events. ${ }^{1}$ Globally, agriculture is thought to directly contribute to between $10 \%$ and $12 \%$ of total greenhouse gas (GHG) emissions, and upto $32 \%$ of global emissions if land-use change is included. ${ }^{2}{ }^{3}$ The need for sustainable food systems to address climate change has been highlighted by the United Nations (UN) and the WHO. ${ }^{4}$

In the UK, the 2010 annual GHG inventory report submitted to the UN Framework Convention on Climate Change estimates that 46.2 million tonnes of carbon dioxide equivalents $\left(\mathrm{tCO}_{2} \mathrm{e}\right)$, approximately $8 \%$ of $\mathrm{GHG}$ emissions produced in the UK, are related to agriculture. ${ }^{6}$ The Climate Change Act was passed by the UK government in 2008 to reduce the UK's GHG emissions by $80 \%$ by 2050 from the 1990 levels, ${ }^{7}$ although projections indicate that the interim target of a $50 \%$ reduction by 2027 is unlikely to be achieved. ${ }^{8}$ 
Recent reviews have suggested that substantial reductions in GHG emissions from agriculture are unlikely through technological improvements alone and will also require changes in food consumption patterns. ${ }^{9} 10$

\section{Food, tax and health}

In the developed world, obesity is a major health problem and is associated with diseases such as diabetes, cardiovascular disease and some cancers. ${ }^{11}$ Furthermore, high intake of specific food groups, such as red and processed meat are also associated with ill-health. ${ }^{12-14}$ Conversely, high intake of other food groups, such as fruit and vegetables, protect against ill-health. ${ }^{15-17}$

Countries are increasingly using taxation to change population eating habits and improve health; examples include the recently withdrawn tax on saturated fat in Denmark, a tax on a variety of unhealthy foods in Hungary and a tax on sweetened drinks in France. ${ }^{18}$ The majority of studies investigating the relationship between food taxation and health are based on modelling, which offers the flexibility to illustrate a range of scenarios. ${ }^{19}$ In modelling taxes, it is important to account for the effect of substituting with other foods as there is the potential that taxes designed to improve health may inadvertently do the opposite, for example, by heavily taxing saturated fat, people may then consume more salt. ${ }^{20}$ In summarising the current evidence from trials and modelling studies, a review by Mytton et $a l^{18}$ suggests that any tax would need to be $20 \%$ or higher to have a significant impact on purchasing patterns and population health.

A tax on foods associated with high GHG emissions could potentially help to internalise the wider cost of GHGs to society; however, it is unclear whether such a tax would have beneficial or harmful side effects on health. ${ }^{21-23}$ Other studies have explored the potential health implications of diets that reduce GHG emissions ${ }^{23-33}$; however, many of these have modelled arbitrary changes in diet that may not reflect possible changes in consumption (eg, replacing red meat with fruit and vegetables) ${ }^{24-27}$ Other studies that have investigated more realistic dietary scenarios do not offer a mechanism to change population dietary habits. ${ }^{28-32}$ Wilson $e t a l^{3}$ identified dietary patterns that were low cost, low in GHG emissions, and beneficial for health, and suggest that fiscal measures may be an appropriate mechanism by which to alter New Zealand dietary habits. Edjabou and Smed are the only authors to have previously modelled the impact on health of internalising the cost of GHG emissions through taxation. ${ }^{23}$ The authors investigated the impact of raising the price of food by either 756 Danish Krone (DKK; £86) or 260 DKK $(£ 30) / \mathrm{tCO}_{2} \mathrm{e}$ on Danish population saturated fat and sugar consumption. However, the magnitude of any subsequent health effects is not quantified. ${ }^{23}$

In order to account for, and internalise, the wider costs to society of climate change from food production and consumption in the UK, we model the effect of a
UK GHG emission food tax on health. Two scenarios are modelled: the first taxes food groups with GHG emissions greater than average and the second taxes high-GHG emission food groups and subsidises those with low emissions to create a revenue-neutral scenario. We show that internalising the costs of GHG emissions in the food system has the potential to reduce GHG emissions, generate significant revenue and save lives.

\section{METHODS}

We use a five-step method to model the impact of a GHG emission food tax on the health of the UK population (as measured by annual deaths averted or delayed, see figure 1$)$.

\section{Step 1: Set the tax rates}

The modelled tax rates are based on the UK government's Department for Environment, Food and Rural Affairs (Defra) agriculture marginal abatement cost curve (MACC) by Moran et $a \hat{l}^{34}$ adjusted to 2010 prices. MACCs are used to prioritise the implementation of GHG abatement strategies. They plot the impact on GHG emissions of different interventions in the order of cost-effectiveness thereby allowing the user to visualise the cost (or savings) of reducing emissions by a specific amount using a given intervention. By plotting the costeffectiveness of different strategies to reduce GHG emissions from agriculture, the agriculture MACC suggests that investment of $£ 24.10 / \mathrm{tCO}_{2} \mathrm{e}\left(£ 27.19 / \mathrm{tCO}_{2} \mathrm{e}, 2010\right.$ prices) can reduce the UK agricultural GHG emissions by $7850 \mathrm{ktCO}_{2} \mathrm{e}(16.2 \%)$, with the next most costeffective abatement strategy costing significantly more (£174.22/ $\mathrm{tCO}_{2} \mathrm{e}, £ 196.60 / \mathrm{tCO}_{2} \mathrm{e}, 2010$ prices). ${ }^{34}$ The specific tax level chosen for this analysis corresponds with the threshold identified in the MACC that allows for substantial reductions of GHG emissions at a cost of $£ 24.10 / \mathrm{tCO}_{2} \mathrm{e}\left(£ 27.19 / \mathrm{tCO}_{2} \mathrm{e}, 2010\right.$ prices$)$. The tax rate selected is also similar to the social cost of carbon for the UK economy of $£ 21-£ 25 / \mathrm{tCO}_{2} \mathrm{e}$ (2010 prices) calculated by the "Stern Review" 35 although it should be noted that estimations of the cost to society of GHG emissions vary markedly. ${ }^{36}$

Two illustrative scenarios are modelled to investigate the impact on health, change in the UK GHG emissions and revenue generated from a GHG emission tax on food

A. GHG emissions tax of $£ 2.72 / \mathrm{tCO}_{2} \mathrm{e} / 100 \mathrm{~g}$ product applied to all food groups with emissions greater than $0.41 \mathrm{kgCO}_{2} \mathrm{e} / 100 \mathrm{~g}$, the mean level of emissions across all food groups;

B. As with (A) but using revenue generated to subsidise food groups with emissions lower than $0.41 \mathrm{kgCO}_{2} \mathrm{e} /$ $100 \mathrm{~g}$ to create a cost-neutral scenario.

The rate of subsidy in scenario (B) was calculated by applying the tax rate of $£ 2.72 \mathrm{tCO}_{2} \mathrm{e} / 100 \mathrm{~g}$ product to the difference between the mean GHG emissions 
Figure 1 Modelling pathwaythe figure highlights the major steps in the modelling pathway used in this research. $\mathrm{tCO}_{2} \mathrm{e}$, tonnes of $\mathrm{CO}_{2}$ equivalents.

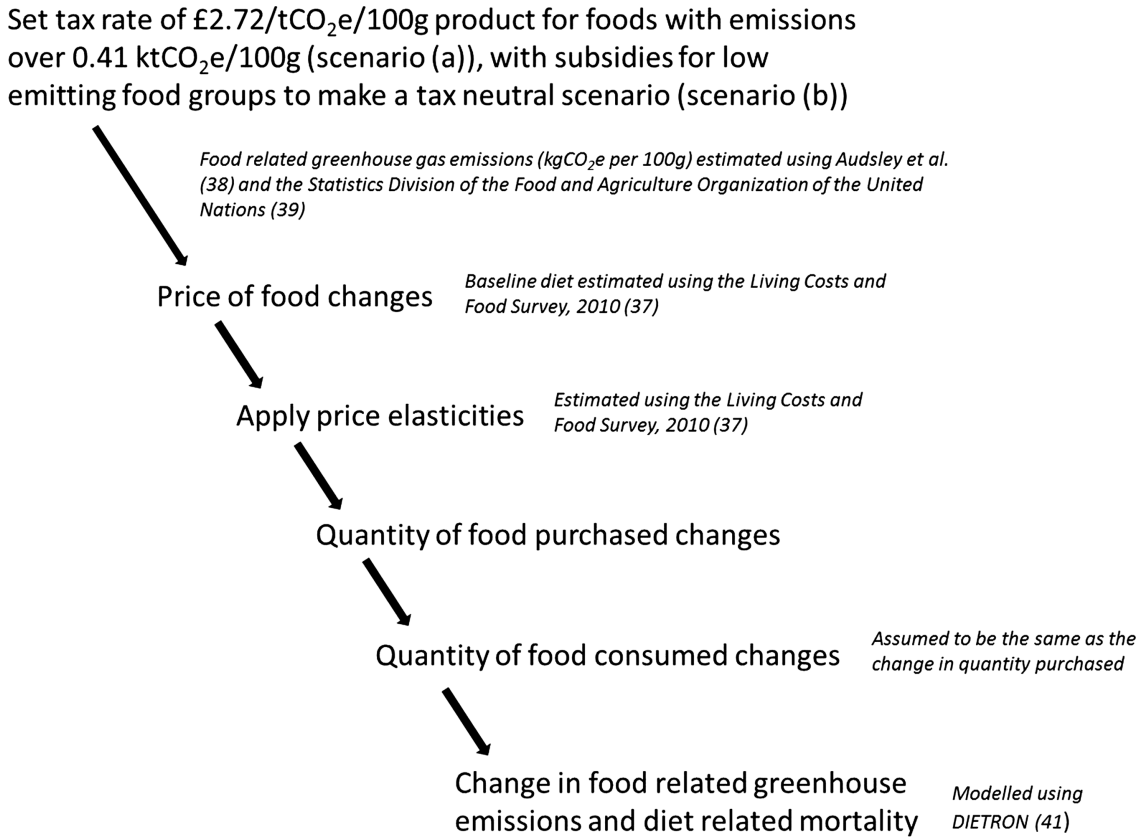

$\left(0.41 \mathrm{kgCO}_{2} \mathrm{e} / 100 \mathrm{~g}\right)$ and the GHG emissions for each food group with emissions below average.

\section{Step 2: Identify baseline consumption data}

Current UK food consumption patterns are taken from the Living Costs and Food Survey (LCF) for 2010, to provide the baseline level of food purchasing prior to the application of a tax. ${ }^{37}$ The LCF is a survey of purchasing data for 256 food categories compiled from 2-week long food expenditure diaries of 12196 people (5263 households) from across the UK. The survey measures purchasing habits and we assumed that all food purchased is consumed.

\section{Step 3: Identify GHG emissions for each food group}

GHG emissions for different food types, measured as $\mathrm{kg}$ of $\mathrm{CO}_{2} \mathrm{e}$ produced for a $\mathrm{kg}$ of product, are taken from Audsley et al the only study to have collated a near complete set of the UK specific GHG emissions for a wide range of food types from literature. ${ }^{38}$ Emissions are divided into three categories: primary production; processing, distribution, retail and preparation; and land-use change.

To derive the level of the tax for each food type, we use the GHG emissions from primary production (up to the retail distribution centre-pre-RDC) and land-use change, and not emissions from processing, distribution, retail and preparation (post-RDC); although the exact distinction of where production stops and processing begins varies slightly between different food groups. ${ }^{38}$ This is because post-RDC emissions for individual food types are not available. Furthermore, post-RDC emissions result from the consumer's travel to buy the food and how the consumer chooses to cook the product. These decisions are as much influenced by the price of fuel and electricity, as food. On a conservative basis, we assume that food purchased in restaurants (not including takeaway meals) will not change in price as a result of the tax (eating out in 2010 contributed only $11 \%$ of daily calorie intake). ${ }^{37}$

Pre-RDC emissions for food categories in the LCF are weighted by the proportion of food consumed in the UK that is domestically produced, imported from Europe and imported from elsewhere in the world using consumption and import data from Food Balance Sheets published by the Statistics Division of the Food and Agriculture Organisation of the UN. ${ }^{39}$

Where Food and Agriculture Organisation Statistical Database (FAOSTAT) food types do not exactly match the food categories used in the LCF, the food categories are either assigned emissions (and therefore a tax rate) of a weighted average of the food comprising that group (eg, fresh fruit), the same emissions as the primary ingredient in the group (eg, bread/cereals/flour are assigned the emissions of wheat) or the emissions of the closest constituent ingredient (eg, cheese is assigned the same emissions as butter).

The GHG emissions for each food type in $\mathrm{kgCO}_{2} \mathrm{e} / \mathrm{kg}$ product are the sum of pre-RDC emissions (weighted by the proportions domestically produced and imported) and land-use change related emissions.

\section{Step 4: Apply price elasticities}

Price elasticities predict the percentage change in the amount of a food purchased, and of its substitute and complementary foods, following a $1 \%$ change in price. The UK specific price elasticities are derived for food categories from the LCF, 2010 using methods described 
in Tiffin and Arnoult. ${ }^{40}$ Using three-stage budgeting, we estimate unconditional price elasticities for 29 different food groups into which each of the 256 food categories of the LCF are allocated. The own-price and cross-price elasticities used in this study are available from the authors on request. These are then used to predict change in purchasing and therefore nutritional composition of the diet and annual tax revenue generated following tax scenarios (A) and (B) (table 1). The annual revenue generated by tax scenario (A) is calculated by scaling up the post-tax per person food intake from the LCF to the UK population and multiplying it by the tax per $\mathrm{kg}$ of each food group.

The $95 \%$ credible intervals of the post-tax estimates of the reduction in GHG emissions, revenue generated and nutritional composition of the diet reflect the uncertainty surrounding the price elasticity estimates. Elasticities are estimated using a Markov Chain Monte Carlo procedure with 12000 iterations and a burn-in of 2000.

\section{Step 5: Identify population health implications of diet post tax}

The effects of the introduction of a food-based GHG emission tax on health are modelled using the DIETRON comparative risk assessment model to derive changes in mortality and identify the number of deaths averted with each scenario. ${ }^{41}$ The DIETRON model uses age-specific and sex-specific relative risk estimates from meta-analyses to link the consumption of different food categories to mortality (figure 2). Dietary input data are grams/day of fruit, vegetables, salt and fibre, percentage of total energy derived from total fat, monounsaturated fatty acids, polyunsaturated fatty acids, saturated fatty acids, trans fatty acids, dietary cholesterol and total energy intake in kilocalories/day (kcal/day) ${ }^{41}$ Changes in the mortality burden of coronary heart disease, stroke and cancer are modelled through the intermediary risk factors of blood pressure, blood cholesterol and obesity. The DIETRON model derives $95 \%$ credible intervals using 5000 iterations of a Monte Carlo analysis to account for the uncertainty of the relationship between the dietary changes and mortality outcomes reported in the literature. The values for all of the parameters in the DIETRON model and the sources from which they are drawn, are provided in the supplementary data of an open access journal article and the complete model is available from the authors on request. ${ }^{42}$

Following the change in UK population diet, the number of people consuming less than the recommended daily intake of vitamins $\mathrm{A}$ and $\mathrm{B}_{12}$, calcium, iron and zinc are estimated. Consumption of micronutrients are assumed to follow a log-normal distribution with mean and SD taken from the National Diet and Nutrition Survey (NDNS) years 1 and 2 (2008/20092009/2010). ${ }^{43}$ NDNS collects 4-day food diaries for 2126 participants as well as blood samples to help assess nutritional status; when calculating the
Table 1 Food groups for which price-elasticities are estimated, and the levels of taxation applied to each food group for tax scenarios (A) and (B)

\begin{tabular}{|c|c|c|c|}
\hline \multirow[b]{2}{*}{ Food group } & \multirow{2}{*}{$\begin{array}{l}\text { GHG } \\
\text { emissions/kg } \\
\text { product } \\
\left(\mathrm{kgCO}_{2} \mathrm{e}\right)\end{array}$} & \multicolumn{2}{|c|}{ Tax/kg product in $£$} \\
\hline & & Scenario (A) & Scenario (B) \\
\hline Milk & 1.8 & 0 & -0.06 \\
\hline $\begin{array}{l}\text { Other milk } \\
\text { products }\end{array}$ & 2.4 & 0 & -0.05 \\
\hline Cream & 2.4 & 0 & -0.05 \\
\hline Cheese & 1.8 & 0 & -0.06 \\
\hline Eggs & 4.9 & 0.02 & 0.02 \\
\hline Pork & 7.9 & 0.10 & 0.10 \\
\hline Beef & 68.8 & 1.76 & 1.76 \\
\hline Poultry & 5.4 & 0.04 & 0.04 \\
\hline Lamb & 64.2 & 1.63 & 1.63 \\
\hline Other meat & 35.9 & 0.86 & 0.86 \\
\hline Fish & 5.4 & 0.03 & 0.03 \\
\hline $\begin{array}{l}\text { Bread/ } \\
\text { cereals/flour }\end{array}$ & 1 & 0 & -0.08 \\
\hline $\begin{array}{l}\text { Cakes/buns/ } \\
\text { pastries/ } \\
\text { biscuits }\end{array}$ & 0.9 & 0 & -0.09 \\
\hline Animal fats & 35.6 & 0.86 & 0.86 \\
\hline $\begin{array}{l}\text { Vegetable } \\
\text { fats }\end{array}$ & 3.2 & 0 & -0.02 \\
\hline $\begin{array}{l}\text { Sugar and } \\
\text { preserves }\end{array}$ & 0.1 & 0 & -0.11 \\
\hline Sweets & 0.1 & 0 & -0.11 \\
\hline $\begin{array}{l}\text { Tinned and } \\
\text { dried fruit } \\
\text { and nuts }\end{array}$ & 0.9 & 0 & -0.09 \\
\hline Fresh fruit & 0.9 & 0 & -0.09 \\
\hline Potatoes & 0.4 & 0 & -0.10 \\
\hline $\begin{array}{l}\text { Canned } \\
\text { vegetables }\end{array}$ & 1.6 & 0 & -0.07 \\
\hline $\begin{array}{l}\text { Fresh } \\
\text { vegetables }\end{array}$ & 1.6 & 0 & -0.07 \\
\hline Fruit juice & 0.9 & 0 & -0.09 \\
\hline Soft drinks & 0.1 & 0 & -0.11 \\
\hline $\begin{array}{l}\text { Non-coffee } \\
\text { hot drinks }\end{array}$ & 3 & 0 & -0.03 \\
\hline Coffee drinks & 10.1 & 0.16 & 0.16 \\
\hline Beer & 3.8 & 0 & -0.01 \\
\hline Wine & 1 & 0 & -0.08 \\
\hline Other & 3.3 & 0 & -0.02 \\
\hline
\end{tabular}

GHG, greenhouse gas emissions; $\mathrm{kgCO}_{2} \mathrm{e}, \mathrm{kg}$ of carbon dioxide equivalents.

distributions we used total micronutrients consumed including supplements. Where recommended daily intakes vary between men and women, the average is used. $^{44}$

\section{RESULTS}

Table 2 shows that following tax scenarios (A) and (B) the largest changes in consumption occurred with beef 
Figure 2 DIETRON model conceptual framework-the figure demonstrates relationships between different components of the DIETRON comparative risk assessment model. Model inputs are to the left of the figure with outcomes on the right and mediating factors in the middle. Solid lines represent a negative health relationship and dashed lines represent a positive relationship.

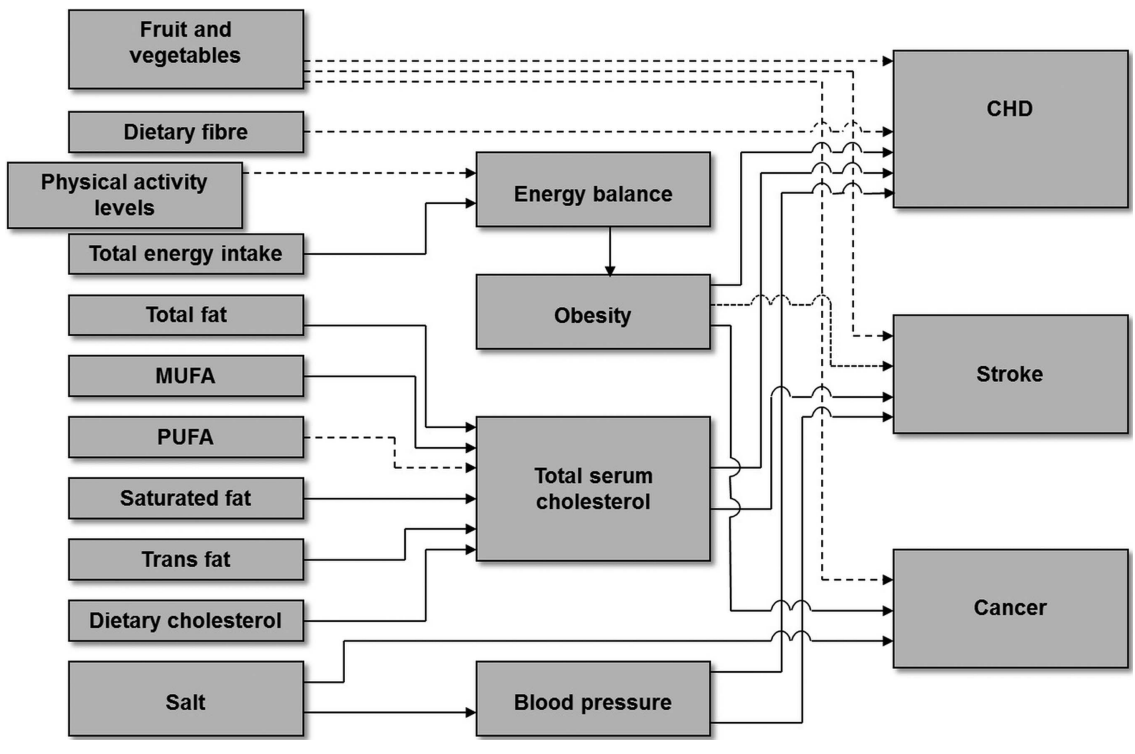

(14.2\% reduction in scenario (A), $13.7 \%$ in scenario (B) ) and lamb (14.1\% and $13.9 \%$ reductions in scenarios (A) and (B), respectively). Unlike scenario (A), scenario (B) led to increases in the consumption of milk, fruit juice, fresh fruit and potatoes by more than $4 \%$. Scenario (B) also resulted in a $5 \%$ increase in sugar

Table 2 Percentage change in consumption of different food groups following the implementation of tax scenarios (A) and (B)

\begin{tabular}{|c|c|c|}
\hline Food group & $\begin{array}{l}\text { Scenario }(\mathrm{A})(95 \% \text { Cls) } \\
\text { Total change in quantity consumed }(\%)\end{array}$ & Scenario (B) (95\% Cls) \\
\hline Milk & $-0.25(-0.44$ to -0.06$)$ & $+6.19(+5.11$ to +7.26$)$ \\
\hline Other milk products & $-0.24(-0.41$ to -0.61$)$ & $+1.79(+1.29$ to +2.28$)$ \\
\hline Cream & $-0.03(-0.13$ to +0.06$)$ & $+0.15(-1.42$ to +1.71$)$ \\
\hline Cheese & $-0.19(-0.32$ to -0.07$)$ & $+0.86(+0.47$ to +1.25$)$ \\
\hline Eggs & $-0.51(-0.76$ to -0.25$)$ & $-0.19(-1.20$ to +0.82$)$ \\
\hline Pork & $-1.20(-1.51$ to -0.89$)$ & $-0.67(-1.04$ to -0.31$)$ \\
\hline Beef & $-14.22(-17.88$ to -10.56$)$ & $-13.71(-17.35$ to -10.01$)$ \\
\hline Poultry & $-0.23(-0.53$ to +0.07$)$ & $-0.30(-0.06$ to +0.67$)$ \\
\hline Lamb & $-14.14(-23.78$ to -4.51$)$ & $-13.91(-23.55$ to -4.27$)$ \\
\hline Other meat & $-9.81(-11.22$ to -8.39$)$ & $-9.13(-10.55$ to -7.71$)$ \\
\hline Fish & $-0.95(-1.89$ to -0.00$)$ & $-0.43(-1.07$ to +0.20$)$ \\
\hline Bread, cereals, flour and other starch & $-0.35(-0.52$ to -0.19$)$ & $+2.21(+1.83$ to +2.59$)$ \\
\hline Cakes, buns, pastries and biscuits & $-0.29(-0.44$ to -0.15$)$ & $+1.29(+0.93$ to +1.65$)$ \\
\hline Animal fats & $-13.25(-16.10$ to -10.40$)$ & $-13.32(-16.26$ to -10.37$)$ \\
\hline Vegetable fats & $+1.09(-0.19$ to +2.36$)$ & $+1.62(+0.20$ to +3.05$)$ \\
\hline Sugar and preserves & $-0.14(-0.64$ to +0.35$)$ & $+5.04(+4.46$ to +5.63$)$ \\
\hline Sweets & $-0.20(-0.61$ to +0.20$)$ & $+0.91(+0.17$ to +1.66$)$ \\
\hline Tinned and dried fruit, and nuts & $+0.07(-0.04$ to +0.17$)$ & $+0.96(+0.60$ to +1.31$)$ \\
\hline Fresh fruit & $+0.18(-0.08$ to +0.43$)$ & $+3.49(+2.79$ to +4.18$)$ \\
\hline Potatoes & $-0.27(-0.38$ to -0.15$)$ & $+3.08(+2.68$ to +3.49$)$ \\
\hline Canned vegetables & $-0.36(-0.50$ to -0.22$)$ & $+1.67(+1.32$ to +2.02$)$ \\
\hline Fresh vegetables & $-0.41(-0.56$ to -0.26$)$ & $+2.39(+1.96$ to +2.82$)$ \\
\hline Fruit juice & $-0.12(-0.26$ to +0.03$)$ & $+9.97(+7.61$ to +12.32$)$ \\
\hline Soft drinks & $-0.20(-0.45$ to +0.04$)$ & $+12.95(+11.16$ to +14.74$)$ \\
\hline Non-coffee drinks & $-0.16(-0.37$ to +0.05$)$ & $+0.26(-0.29$ to +0.82$)$ \\
\hline Coffee drinks & $-1.20(-1.41$ to -0.99$)$ & $-1.11(-1.71$ to -0.51$)$ \\
\hline Beer & $-0.13(-0.54$ to +0.29$)$ & $+0.06(-0.70$ to +0.82$)$ \\
\hline Wine & $-0.15(-0.63$ to +0.33$)$ & $+0.77(-0.12$ to +1.66$)$ \\
\hline Other alcoholic beverages & $-0.12(-0.52$ to +0.28$)$ & $-0.07(-0.80$ to +0.66$)$ \\
\hline
\end{tabular}


Table 3 Nutrient composition of baseline diet and diets following tax scenarios $(A)$ and $(B)$, alongside the UK recommended daily intakes

\begin{tabular}{|c|c|c|c|c|}
\hline & Baseline & $\begin{array}{l}\text { Scenario }(A) \\
\text { (95\% credible intervals) }\end{array}$ & $\begin{array}{l}\text { Scenario (B) } \\
\text { (95\% credible intervals) }\end{array}$ & Recommended daily intake ${ }^{44}$ \\
\hline Energy (kcal/day) & 2027 & 1999 (1997 to 2002) & 2048 (2044 to 2051$)$ & Female 2000; male 2500 \\
\hline Total fat (g/day) & 84.2 & 82.4 (82.2 to 82.6$)$ & 83.6 (83.4 to 83.9$)$ & \\
\hline SAFAs (g/day) & 32.5 & 31.6 (31.5 to 31.7$)$ & 32.1 (32.0 to 32.2$)$ & Female $<20$; male $<30$ \\
\hline MUFAs (g/day) & 31 & 30.3 (30.2 to 30.4$)$ & 30.7 (30.6 to 30.8$)$ & \\
\hline PUFAs (g/day) & 15.3 & $15.2(15.1$ to 15.2$)$ & $15.4(15.3$ to 15.4$)$ & \\
\hline Cholesterol (mg/day) & 230 & 222.6 (221.8 to 223.3 ) & 225.1 (224.1 to 226.0 ) & \\
\hline Fibre (g/day) & 13.1 & $13.1(13.0$ to 13.1$)$ & $13.4(13.4$ to 13.4$)$ & 18 \\
\hline Salt (g/day) & 6.3 & $6.2(6.2$ to 6.2$)$ & $6.3(6.3$ to 6.3$)$ & 6 \\
\hline Fruit and vegetables (g/day) & 344.2 & 343.6 (343.2 to 344.1$)$ & 355.9 (354.4 to 357.3$)$ & 400 \\
\hline Iron (mg/day) & 10.6 & $10.4(10.4$ to 10.4$)$ & $10.6(10.6$ to 10.7$)$ & Female 14.8; male 8.7 \\
\hline Calcium (mg/day) & 889.1 & 884.3 (883.4 to 885.2$)$ & 915.1 (911.9 to 918.5$)$ & 700 \\
\hline Zinc (mg/day) & 8.2 & $8.0(8.0$ to 8.0$)$ & 8.2 (8.1 to 8.2$)$ & Female 4-7; male 5.5-9.5 \\
\hline Vitamin A ( $\mu \mathrm{g} /$ day) & 803.6 & 778.4 (775.6 to 780.9$)$ & 793.7 (790.6 to 796.6$)$ & Female 600 ; male 700 \\
\hline Vitamin D ( $\mu \mathrm{g} /$ day) & 2.7 & 2.6 (2.6 to 2.6$)$ & 2.7 (2.7 to 2.7 ) & Variable \\
\hline Vitamin $B_{12}(\mu \mathrm{g} /$ day $)$ & 5.7 & 5.6 (5.6 to 5.6$)$ & $5.8(5.7$ to 5.8$)$ & 1.5 \\
\hline Total sugar (g/day) & 115.4 & 115.0 (114.9 to 115.2$)$ & 120.3 (119.8 to 120.6$)$ & \\
\hline
\end{tabular}

and preserves consumption and a $12.9 \%$ increase in soft drink consumption (compared to a $0.2 \%$ non-significant reduction in scenario $(\mathrm{A}))$.

Tax scenario (A) predicted a change in energy intake from $2027 \mathrm{kcals} /$ day to $1999 \mathrm{kcals} /$ day $(95 \%$ credible intervals 1997 to $2002 \mathrm{kcals} /$ day), a $1.4 \%$ reduction (table 3). There were also overall reductions in consumption of cholesterol, saturated fatty acids, polyunsaturated fatty acids, total fat and in zinc, vitamin $\mathrm{A}$ and vitamin $\mathrm{B}_{12}$ by more than $2 \%$ (mean levels of zinc, vitamin $A$ and vitamin $B_{12}$ remained above the $U K$ daily recommended intake). All other nutrients and dietary constituents increased or decreased by less than $2 \%$.

Tax scenario (B) resulted in an increase in calorie consumption from 2027 to $2048 \mathrm{kcals} /$ day (20442052 kcals/day), a $1 \%$ increase (table 3). In this scenario there was a reduction in cholesterol consumption of $2.2 \%$, and increases in consumption of fruit and vegetables, calcium and sugar of over $2 \%$. The remaining nutrients did not vary from baseline by more than $2 \%$.

Following changes in nutrient consumption, tax scenarios (A) and (B) predict shifts in the number of people consuming below the recommended daily amounts of dietary micronutrients (see online supplementary table S1). ${ }^{44}$ Following tax scenario (A), over 900000 extra people consumed less than the recommended daily intake of vitamin A, zinc and iron. Tax scenario (B) predicted 1507000 extra people would be consuming greater than the recommended daily intake of calcium.

Scenario (A) predicted 7768 deaths delayed or averted in the UK population per year $(95 \%$ credible intervals 7151 to 8382 deaths) and 2448 delayed or averted in people under 75 years (table 4 ). Most of the reduction in deaths was due to fewer calories consumed; this leads to changes in population obesity prevalence and a lower burden of cardiovascular disease (tables 4 and 5). If energy intake were to have stayed the same, the improvement in dietary quality would have led to 1207 deaths (1003 to 1431) delayed or averted.

Scenario (B) predicted an increase in deaths in the UK population of 2685 (1966 to 3402) and of 477 in those less than 75 years (table 4 ). The increase in deaths was due to increased calories consumed, again leading to a change in obesity prevalence and a greater burden of cardiovascular disease (tables 4 and 5). If energy intake were to have stayed the same, the increase in dietary quality would have led to 2536 (2195 to 2896) deaths delayed or averted.

In scenario (A), $75 \%$ of deaths averted were due to a reduction in cardiovascular disease and $12 \%$ to cancer; in scenario (B), $72 \%$ of the increase in premature deaths was due to an increase in cardiovascular disease (table 5).

Table 6 shows that scenario (A) resulted in a reduction in GHG emissions of $18683 \mathrm{ktCO}_{2} \mathrm{e}(95 \%$ credible intervals, $14665 \mathrm{ktCO}_{2} \mathrm{e}$ to $\left.22889 \mathrm{ktCO}_{2} \mathrm{e}\right)$. The predicted revenue generated from this scenario was $£ 2023$ million (£1980 million to $£ 2064$ million). Scenario (B) resulted in a $15228 \mathrm{ktCO}_{2} \mathrm{e}\left(11245 \mathrm{ktCO}_{2} \mathrm{e}\right.$ to $\left.19492 \mathrm{ktCO}_{2} \mathrm{e}\right)$ reduction in GHG emissions. The reduction in emissions attributable to land-use change in scenario (A) accounted for $76 \%$ of the total reduction and for $84 \%$ in scenario (B).

\section{DISCUSSION}

Our results show that fiscal interventions to reduce GHG emissions from the food sector may have health cobenefits. In scenario (A), taxation at a rate of $£ 2.72$ / $\mathrm{tCO}_{2} \mathrm{e} / 100 \mathrm{~g}$ product has the potential to reduce the burden of premature deaths in the UK by 7768 /year $(1.4 \% \text { of all UK deaths })^{45}$ at the same time reducing 
Table 4 Total deaths delayed or averted by age and deaths delayed or averted from nutritional changes in the diet following taxation scenarios $(A)$ and $(B)^{*}$

\begin{tabular}{|c|c|c|c|c|}
\hline & \multicolumn{4}{|c|}{ Deaths averted or delayed, scenarios (A) and (B) } \\
\hline & \multicolumn{2}{|c|}{ Scenario (A) (95\% credible intervals) } & \multicolumn{2}{|c|}{ Scenario (B) (95\% credible intervals) } \\
\hline & Energy intake changes & $\begin{array}{l}\text { Energy intake stays } \\
\text { the same }\end{array}$ & Energy intake changes & $\begin{array}{l}\text { Energy intake stays } \\
\text { the same }\end{array}$ \\
\hline Total & 7768 (7151 to 8392) & 1207 (1003 to 1431$)$ & $-2685(-3402$ to -1966$)$ & 2536 (2195 to 2896) \\
\hline $\begin{array}{l}\text { Total under } \\
75 \text { years }\end{array}$ & 2448 (2254 to 2638 ) & 463 (386 to 542 ) & $-477(-719$ to -233$)$ & 1082 (945 to 1223$)$ \\
\hline $\begin{array}{l}\text { Fruit and } \\
\text { vegetables }\end{array}$ & $-75(-124$ to -26$)$ & 696 (540 to 857 ) & 1996 (1570 to 2420$)$ & 1414 (1118 to 1712$)$ \\
\hline Fibre & $-118(-50$ to -185$)$ & 188 (79 to 298$)$ & 439 (185 to 695$)$ & 204 (83 to 326 ) \\
\hline Fats & 410 (324 to 512$)$ & 373 (292 to 464$)$ & 577 (432 to 735$)$ & 601 (454 to 765$)$ \\
\hline Salt & 426 (356 to 496$)$ & 98 (81 to 114$)$ & $-32(-37$ to -26$)$ & 216 (181 to 252$)$ \\
\hline Energy balance & 7124 (6511 to 7737$)$ & ot & $-5726(-6212$ to -5229$)$ & $0 \dagger$ \\
\hline $\begin{array}{l}\text { Alcohol } \\
\text { consumption }\end{array}$ & $15(11$ to 19$)$ & $-148(-187$ to -107$)$ & $-13(-16$ to -9$)$ & 108 (79 to 137$)$ \\
\hline
\end{tabular}

food-related GHG emissions by $18683 \mathrm{ktCO}_{2} \mathrm{e}$ and generating up to $£ 2.02$ billion revenue. When subsidising products with GHG emissions lower than the average emissions per $\mathrm{kg}$ of food consumed in the UK (scenario (B)), we predict a reduction in emissions of $15228 \mathrm{ktCO}_{2} \mathrm{e}$ with an increase in premature mortality of 2685 ( $0.5 \%$ of UK deaths). ${ }^{45}$

Scenario (B; revenue neutral) demonstrates how health and sustainability goals are not always aligned and results in some proposed price changes that run against the current trend in public health (eg, subsidising sugar and soft drinks by $11 \mathrm{p} / \mathrm{kg}$ due to the low level of GHG emissions associated with sugar). The relationship between food consumption and health is more politically prominent than that between food consumption and the environment, and therefore it is unlikely that a taxation system could be introduced that did not take account of effects on health and address them.

A concern regarding diets that would lead to reduced GHG emissions is that they may result in a decrease in consumption of essential micronutrients. Both modelled scenarios maintain the same broad micronutrient composition as the baseline diet with only moderate reductions in mean vitamins $A$ and $B_{12}$ consumption seen in scenario (A; but these were still within recommended daily levels). Despite small absolute percentage changes in micronutrient consumption, at a population level there may be significant changes to the number of people consuming below the recommended daily intakes (see online supplementary table S1).

\section{Strengths and limitations}

This study is the first to model the impact on population mortality of internalising the societal cost of food-related GHG emissions through increasing price. A strength of this work is that we are able to estimate the effect of price changes on both the taxed product and on substituting and complementing products. Furthermore both consumption and price elasticity data are derived from the same dataset (LCF), resulting in a more accurate modelling of the changes in purchasing and consumption than previous modelling studies in this area. ${ }^{20} 22$

Limitations of this work include that the estimates of GHG emissions of some products are assumed to be

Table 5 Total deaths delayed or averted by cause following taxation scenarios $(A)$ and $(B)$ allowing for energy intake to change

\begin{tabular}{lcc} 
& Deaths averted or delayed & \\
\cline { 2 - 3 } & Scenario (A) (95\% credible intervals) & Scenario (B) (95\% credible intervals) \\
\hline Cardiovascular disease & $5845(5274$ to 6410$)$ & $-1937(-2583$ to -1293$)$ \\
Diabetes & $477(381$ to 580$)$ & $-399(-486$ to -313$)$ \\
Cancer & $969(798$ to 1138$)$ & $30(-240$ to 305$)$ \\
Kidney disease & $79(39$ to 123$)$ & $-63(-100$ to -32$)$ \\
Liver disease & $392(264$ to 524$)$ & $-323(-434$ to -217$)$
\end{tabular}

${ }^{*}$ Positive numbers indicate deaths delayed or averted. 
Table 6 Reduction in greenhouse gas emissions and revenue generated from tax scenarios (A) and (B)

\begin{tabular}{|c|c|c|}
\hline & Scenario (A) (95\% credible intervals) & $\begin{array}{l}\text { Scenario (B) (95\% credible } \\
\text { intervals) }\end{array}$ \\
\hline Reduction in total emissions & $18683 \mathrm{ktCO}_{2} \mathrm{e}(14665$ to 22889 & $15228 \mathrm{ktCO}_{2} \mathrm{e}(11245$ to 19492$)$ \\
\hline $\begin{array}{l}\text { Reduction in emissions from land-used } \\
\text { change }\end{array}$ & $14138 \mathrm{ktCO}_{2} \mathrm{e}(11042$ to 17377$)$ & $12837 \mathrm{ktCO}_{2} \mathrm{e}(9744$ to 16 090) \\
\hline Revenue generated & $\begin{array}{l}£ 2023 \text { million ( } 1980 \text { million to } £ 2064 \\
\text { million) }\end{array}$ & $\mathrm{N} / \mathrm{A}$ \\
\hline
\end{tabular}

identical to related products (eg, all tree fruits except oranges are assumed to be the same as apples) and non-UK data are used in some circumstances (eg, with fish). ${ }^{38}$ Estimates of GHG emissions for some imported products are not known and are assumed to be the same as imported products from elsewhere in the world. GHG emissions from land-use change are likely to vary significantly between and within countries and these variations are not captured by this research. Furthermore, the uncertainties surrounding the estimations of GHG emissions are not modelled; these will vary between different food products and between different producers with some (such as milk and beef) ${ }^{46}$ having greater uncertainty than others. ${ }^{38}$ The LCF has a significant non-response rate $(50 \%$ response rate in Great Britain and $59 \%$ in Northern Ireland) and although the results are weighted for non-response, the results may not be representative of the UK population with certain age and income groups likely to be undersampled. ${ }^{47}$

In this study, we base estimates of pretax and post-tax diets on the mean population diet. Population diet will vary between individuals and they may respond to price changes differently both in terms of purchasing and food waste depending on their age and baseline consumption patterns. We do not account for these in our uncertainty estimates because the LCF reports at the household rather than individual level making it impossible to derive age or consumption specific price elasticities; our uncertainty estimates are therefore conservative. We are likely to have over estimated the population consuming below recommended daily intakes because we chose to use adult recommendations but the mean and distributions of consumption are estimated for all ages. Furthermore, it was necessary to compromise between the number of food groups for which own-price and cross-price elasticities are estimated and the confidence with which those estimates were made; greater numbers of food groups result in less confidence in the estimates. We disaggregated the diet into 29 different groups and it is likely that within groups (eg, vegetable fats) certain constituents will vary (sunflower oil, rapeseed oil, etc) but we assumed that the percentage change in consumption for any group applied to all foods within that group.

The uncertainty analyses from which the credible intervals are derived only estimate the parametric uncertainty attached to these estimates (eg, the relationship between calorie intake and obesity) and cannot estimate the structural uncertainty (ie, the uncertainty underlying the design of the model). Structural limitations include: the model assumes no-time lag between changes in consumption behaviour and health outcomes; the model is cross-sectional and therefore cannot predict changes in life expectancy in the counterfactual scenario; it assumes that all non-food items will remain at the same price in the counterfactual scenario; and it assumes that reduction in consumption of broad food categories will be met equally by all items within that category.

We assume that all food purchased is consumed; food waste is no longer accounted for in the LCF and it is possible that the change in purchasing resulting from price increases could have a smaller impact on consumption patterns through individuals reducing food waste. Therefore, individuals may maintain calorie consumption with reduced food purchasing following higher prices, this is thought to be partly driving the reduction in the UK food and drink wastage between 2009 and 2011, a period of rising food prices and falling disposable incomes. ${ }^{48}$ There would likely be differential changes in food waste patterns with different price changes making modelling of these circumstances difficult.

In our study we assume that calorie consumption will change following the implementation of a tax. Both scenarios modelled in this paper show small changes in calorie intake $(1.4 \%$ decrease in scenario (A) and $1 \%$ increase in scenario (B), table 3). Although the changes in calorie intake dominate the modelled changes in mortality (table 4), the changes are considerably fewer than calorie reductions modelled in previous studies of taxes on GHGs or soft drinks (where calories are not assumed to be replaced), which suggest that they are plausible. $^{23} 4950$ Extra calories consumed in scenario (B) are primarily due to increases in consumption of bread and cereals and milk and soft drinks.

In scenarios (A) as well as (b), there is a reduction in premature deaths if energy intake remains the same indicating that the post-tax diet is healthier in other respects (table 4). Although this estimate assumes that the percentage change in calories required to keep energy intake the same leads to a diet with equivalent percentage changes to individual nutritional 
components. Finally, the health impact following the implementation of tax scenarios (A) and (B) is only quantified through the change in diet. We are likely to have underestimated the wider benefits to health of reduced GHG emissions from reduced environmental pollution and slowed climate change within the UK and around the world.

\section{Comparisons with other studies}

The 2006 Stern Review assessed the implications of climate change on the global economy and described climate change as "the greatest and widest-ranging market failure ever seen." "T5 The review went on to calculate the social cost of carbon to society as $\$ 25-\$ 30 / \mathrm{tCO}_{2} \mathrm{e}$ emitted (£16-£19/ $\mathrm{tCO}_{2} \mathrm{e}, 2000$ prices; £21-£25/ $\mathrm{tCO}_{2} \mathrm{e}, 2010$ prices).$^{35}$ Our tax rates are not dissimilar to the social costs to society calculated by the Stern Review and allow for direct comparison between our modelled reduction in GHG emissions to the Defra abatement statistics derived for the agriculture MACC. ${ }^{34}$ We estimate that GHG emissions from production and land-use change for the UK food consumption amount to $249207 \mathrm{ktCO}_{2} \mathrm{e}$; the reduction in GHG emissions seen in scenario (A) of $18683 \mathrm{ktCO}_{2} \mathrm{e}$ equates to $7.5 \%$ of these emissions. This is substantially more than the $7850 \mathrm{ktCO}_{2} \mathrm{e}$ reduction in GHG emissions estimated by Defra's agriculture MACC with an equivalent investment of $£ 24.10 / \mathrm{tCO}_{2} \mathrm{e}(£ 27.19 /$ $\mathrm{tCO}_{2} \mathrm{e}, 2010$ prices). ${ }^{34}$ However, unlike the agriculture MACC, our model incorporates emissions from UK consumed food that is produced overseas. Imported products account for the vast majority of emissions relating to land-use change. Without land-use change, the reduction in emissions from scenarios (A) and (B) are both less than that estimated by Moran $e t a l^{44}$ at $4545 \mathrm{ktCO}_{2} \mathrm{e}$ and $2441 \mathrm{ktCO}_{2} \mathrm{e}$, respectively.

Scenario (B) results in a reduction in GHG emissions of $15228 \mathrm{ktCO}_{2} \mathrm{e}$ which is less than the reduction in scenario (A). It may be expected that by subsidising foods with below-average GHG emissions there would be an even greater reduction in emissions than found in scenario (A); however, the effect of substituting to other foods, in particular to milk, means that the reduction in GHG emissions is not as marked. It should be noted that although scenario (B) results in an overall increase in calorie intake of $1 \%$ (because of increased food consumption) and scenario (A) results in a decrease of $1.4 \%$, this makes little difference to the overall GHG emissions; if calorie consumption were to stay the same as baseline in both scenarios, there would still be an $18428 \mathrm{ktCO}_{2} \mathrm{e}$ reduction in scenario (A) compared to $15436 \mathrm{ktCO}_{2} \mathrm{e}$ reduction in scenario (B).

The number of deaths delayed or averted are fewer than those predicted by Scarborough et $a t^{27}$ who modelled the health impact of three sustainable dietary scenarios, and by Friel et $a l^{25}$ who modelled the health benefits of various strategies to reduce agricultural GHG emissions. However, neither study quantified realistic counterfactual dietary scenarios. Friel et $a l^{25}$ modelled the effect on ischaemic heart disease of a $30 \%$ reduction in livestock consumption leading to less saturated fat and cholesterol intake, without accounting for any effect of substituting food products, and Scarborough et $a l^{27}$, following the UK Committee on Climate Change Fourth Carbon Budget dietary scenarios, assumed that replacement calories from a $50 \%$ reduction in livestock consumption were exclusively derived from fruits, vegetables, and cereals.

Edjabou and Smed $^{23}$ investigated the impact of a GHG tax on food in Denmark and identify identical patterns of reductions in GHG emissions and subsequent changes to population food consumption as in our study. Edjabou and Smed find that applying a non-tax neutral scenario results in a greater reduction in emissions than a tax neutral scenario and that the non-tax neutral scenario reduces overall calorie consumption compared to an increase in the tax neutral model. Similarly, both our model and the Edjabou and Smed model identify large reductions in saturated fat consumption alongside small changes in sugar consumption with the non-neutral scenario and the opposite following the tax neutral scenario. Edjabou and Smed's model does not include the effect of land-use change, and furthermore, their non-tax neutral scenario models the effect of increasing the price of all food rather than just food groups with above the average emissions. However, their estimate of the reduction in GHG emissions from food consumed in Denmark of between $4 \%$ and $7.9 \%$ using a tax rate of $£ 19.10 / \mathrm{tCO}_{2} \mathrm{e}$ is comparable to the $7.5 \%$ reduction we observe in the equivalent scenario (A) with a tax rate of $£ 27.20 / \mathrm{tCO}_{2} \mathrm{e}$ applied just to food groups with emissions greater than average. ${ }^{23}$

\section{Implications and future research}

Scenario (A) is predicted to generate $£ 2.02$ billion revenue/annum. This represents a substantial amount of money that could be reinvested in GHG emission mitigation strategies in either the agriculture sector or elsewhere. However, revenue may also be spent on GHG producing projects that would otherwise have not been funded, thereby negating the reductions in GHG emissions seen with the changes in diet modelled here. Although our modelled tax scenarios lead to a healthier diet, scenario (A) would likely be economically regressive meaning that the poor spend proportionately more of their income on the tax than the rich. However, because those in lower socioeconomic classes suffer from a greater prevalence of chronic disease ${ }^{51}$ and are more sensitive to price changes, ${ }^{52}$ the taxes are likely to be progressive in terms of health benefits. Further work should explicitly consider differential effects by sociodemographic group of internalising the societal cost of climate change in the food sector; this is not currently possible with our data. Alongside this work, there should be greater exploration of the effects of different tax rates and models to explore whether the synergies and conflicts identified in this research may be negated or 
reversed. Our research also estimates a $14 \%$ reduction in lamb and beef consumption, which will have significant negative economic implications for some farmers. We have not accounted for these wider economic impacts; appropriate reinvestment of the tax revenue may help to mitigate the negative consequences.

We are using taxation to internalise much of the cost to society of GHG emissions as it is a readily grasped mechanism for changing prices; however, these price changes could be realised through a different mechanism, for example, carbon trading schemes that incorporate all GHGs relevant to agriculture. The taxes modelled here are not unrealistic; the highest rate of tax is $£ 0.176 / 100 \mathrm{~g}$ beef, which represents a price increase of approximately $15-35 \%$ (depending on quality and type of beef purchased). This price increase is not dissimilar to Mytton et $a l \mathrm{~s}^{18}$ estimate of a $20 \%$ increase in the price of 'unhealthy' foods to give a significant population health benefit and is significantly less than the current tax on cigarettes of $16.5 \%$ of retail plus a further $£ 3.35$ per 20 cigarettes. ${ }^{53}$ As discussed by Mytton et al ${ }^{18}$, taxation of unhealthy food as a public health measure is beginning to gain traction in the developed world yet the jump to taxing foods with high GHG emissions is unlikely to happen soon. Scenario (B) indicates that health and sustainability goals may not always be aligned and therefore an appropriate next step would be to investigate the health and environmental impacts of a combined GHG emission and unhealthy food tax (eg, implementing tax scenario (A) alongside a tax on soft drinks).

\section{CONCLUSIONS}

In the context of widespread global economic austerity and the estimated long-term financial costs of carbon, ${ }^{35} 54$ the health, economic and environmental benefits make internalising these costs through a GHG emission tax on food a potential solution. Current projections estimate that the UK is unlikely to meet the 2050 target of an $80 \%$ reduction in GHG emissions set by the Climate Change $\mathrm{Act}^{7} 8$ and large changes to the food chain supply system would be required to achieve just a $70 \%$ reduction in emissions from agriculture (not including land-use change). ${ }^{38}$ The careful use of market governance mechanisms will have a crucial role in reducing global agriculture GHG emissions and our results show that taxation offers a possible method to reduce GHG emissions, improve public health and raise revenue simultaneously.

\section{Author affiliations \\ ${ }^{1}$ British Heart Foundation Health Promotion Research Group, Nuffield Department of Population Health, University of Oxford, Oxford, UK ${ }^{2}$ School of Agriculture, Policy and Development, University of Reading, Reading, UK \\ ${ }^{3}$ Food Climate Research Network, University of Oxford, Oxford, UK}

Contributors PS had the original idea for the study. AB coordinated the study, designed the study methodology and ran the modelling except for the calculation and application of price elasticities. RT designed the economic modelling for devising price elasticities. AK devised how to apply the tax strategy to price elasticities and ran the economic modelling. PS designed the model to determine health outcomes. $A B$ wrote the initial draft of the manuscript. PS, AK, RT, TG and MR all commented on and contributed to the study methodology and edited various drafts of the final manuscript.

Funding This research received no specific grant from any funding agency in the public, commercial or not-for-profit sectors. $A B$ is an NIHR funded Academic Clinical Fellow in Public Health. MR and PS are funded by grant 021/P\&C/Core/2010/HPRG by the British Heart Foundation, who had no part in the research design, process, or manuscript preparation.

\section{Competing interests None.}

Provenance and peer review Not commissioned; externally peer reviewed.

Data sharing statement Price elasticity data are available from the authors on request. The values for all of the parameters in the DIETRON model, and the sources from which they are drawn, are provided in the supplementary data of an open access journal article and the complete model is available from the authors on request.

Open Access This is an Open Access article distributed in accordance with the Creative Commons Attribution Non Commercial (CC BY-NC 3.0) license, which permits others to distribute, remix, adapt, build upon this work noncommercially, and license their derivative works on different terms, provided the original work is properly cited and the use is non-commercial. See: http:// creativecommons.org/licenses/by-nc/3.0/

\section{REFERENCES}

1. Costello A, Abbas M, Allen A, et al. Managing the health effects of climate change: Lancet and University College London Institute for Global Health Commission. Lancet 2009;373:1693-733.

2. Solomon S, Qin M, Manning M, et al. Section 2.10.2, Direct Global Warming Potentials, in Contribution of Working Group I to the Fourth Assessment Report of the Intergovernmental Panel on Climate Change. London, 2007. http://www.ipcc.ch/publications_and_data/ ar4/wg1/en/ch2s2-10-2.html

3. Bellarby J, Foereid B, Hastings A, et al. Cool farming: climate impacts of agriculture and mitigation potential. Amsterdam, 2008.

4. United Nations Environment Programme. Avoiding Future Famines: Strengthening the Ecological Foundation of Food Security through Sustainable Food Systems. Nairobi, 2012.

5. World Health Organisation. Protecting health from climate change. Geneva, 2009.

6. Brown K, Cardenas L, MacCarthy J, et al. UK Greenhouse Gas Inventory, 1990 to 2010. Annual report for submission under the Framework Convention on Climate Change. Didcot, 2012.

7. UK Government. Climate Change Act 2008. London, 2008. http:// www.legislation.gov.uk/ukpga/2008/27/contents

8. Cambridge Econometrics. The decline in UK's carbon emissions is set to accelerate after 2020 as power generation, helped by a rising flood price of carbon on fossil fuel inputs, makes good progress towards decarbonisation. Cambridge, 2011. http://www.camecon. com/uk/ukenergy/pressrelease-UKenergy.aspx

9. Foresight. The future of food and farming. Final project report. London, 2011.

10. Foley JA, Ramankutty N, Brauman KA, et al. Solutions for a cultivated planet. Nature 2011;478:337-42.

11. World Health Organisation. Diet, Nutrition and the Prevention of Chronic Diseases. Technical Report Series 916. Geneva, 2003.

12. Micha R, Wallace S, Mozaffarian D. Red and processed meat consumption and risk of incident coronary heart disease, stroke and diabetes mellitus. A systematic review and meta-analysis. Circulation 2010;121:2271-83.

13. Pan A, Sun Q, Bemstein AM, et al. Red meat consumption and mortality: results from 2 prospective cohort studies. Arch Intem Med 2012;172:555-63.

14. Chan DS, Lau R, Aune D, et al. Red and processed meat and colorectal cancer incidence: meta-analysis of prospective studies. PLOS ONE 2011;6:e20456.

15. Aune D, Chan DSM, Lau R, et al. Dietary fibre, whole grains, and risk of colorectal cancer: systematic review and dose-response meta-analysis of prospective studies. BMJ 2011;343:d6617.

16. Dauchet L, Amouyel P, Dallongeville J. Fruit and vegetable consumption and risk of stroke: a meta-analysis of cohort studies. Neurology 2005;65:1193-7.

17. Dauchet L, Amouyel P, Hercberg S, et al. Fruit and vegetable consumption and risk of coronary heart disease: a meta-analysis of cohort studies. J Nutr 2006;136:2588-93. 
18. Mytton O, Clarke D, Rayner M. Taxing unhealthy food and drinks to improve health. BMJ 2012;344:e2931.

19. Thow AM, Jan S, Leeder S, et al. The effect of fiscal policy on diet, obesity and chronic disease: a systematic review. Bull World Health Organ 2010;88:609-14.

20. Nnoaham KE, Sacks G, Rayner M, et al. Modelling income group differences in the health and economic impacts of targeted food taxes and subsidies. Int J Epidemiol 2009;38:1324-33.

21. Feng K, Hubacek K, Guan D, et al. Distributional effects of climate change taxation: the case of the UK. Environ Sci Technol 2010;44:3670-6.

22. Wirsenius S, Hedenus F, Mohlin K. Greenhouse gas taxes on animal food products: rationale, tax scheme and climate mitigation effects. Climatic Change 2011;108:159-84.

23. Edjabou L, Smed S. The effect of using consumption taxes on foods to promote climate friendly diets-the case of Denmark. Food Policy 2013;39:84-96.

24. McMichael AJ, Powles JW, Butler CD, et al. Food, livestock production, energy, climate change, and health. Lancet 2007;370:1253-63.

25. Friel S, Dangour AD, Garnett T, et al. Public health benefits of strategies to reduce greenhouse-gas emissions: food and agriculture. Lancet 2009;374:2016-25.

26. Garnett T. Cooking up a storm. Food, greenhouse gas emissions and our changing climate. Guildford, 2008.

27. Scarborough $\mathrm{P}$, Allender S, Clarke D, et al. Modelling the health impact of environmentally sustainable dietary scenarios in the UK. Eur J Clin Nutr 2012;66:710-15.

28. Vieux $F$, Soler L, Touazi $\mathrm{D}$, et al. High nutritional quality is not associated with low greenhouse gas emissions in self-selected diets of French adults. Am J Clin Nutr 2013:97:569-83.

29. Saxe H, Larsen TM, Mogensen L. The global warming potential of two healthy Nordic diets compared with the average Danish diet. Climatic Change 2013;116:249-62.

30. Macdiarmid J, Kyle J, Horgan G, et al. Livewell: a balance of healthy and sustainable food choices. London, 2011.

31. Macdiarmid J, Kyle J, Horgan G, et al. Sustainable diets for the future: can we contribute to reducing greenhouse gas emissions by eating a healthy diet? Am J Clin Nutr 2012;96:632-9.

32. Aston LM, Smith JN, Powles JW. Impact of a reduced red and processed meat dietary pattern on disease risks and greenhouse gas emissions in the UK: a modelling study. BMJ Open 2012;2: e001072.

33. Wilson N, Nghiem N, Ni Mhurchu C, et al. Foods and dietary patterns that are healthy, low-cost, and environmentally sustainable: a case study of optimization modeling for New Zealand. PLOS ONE 2013;8:e59648.

34. Moran D, MacLeod M, Wall E, et al. UK Marginal Abatement Cost Curves for the Agriculture and Land Use, Land-Use Change and Forestry Sectors out to 2022, with Qualitative Analysis of Options to 2050. Report to the Committee on Climate Change. London, 2008.

35. Stern N. Stern Review: The Economics of Climate Change. London, 2006.
36. Ackerman F, Stanton EA. Climate Risks and Carbon Prices: Revising the Social Cost of Carbon. Economics 2012;6:2012-10.

37. Department for the Environment Food and Rural Affairs. Family Food 2010. London, 2011.

38. Audsley E, Brander M, Chatterton J, et al. How low can we go? An assessment of greenhouse gas emissions from the UK food system and the scope to reduce them by 2050. Food Climate Research Network-WWF-UK, 2009

39. FAOSTAT. The Statistics Division of the Food and Agriculture Organisation of the United Nations. 2012. http://faostat.fao.org/ (accessed 7 Jun 2013)

40. Tiffin R, Arnoult M. The demand for a healthy diet: estimating the almost ideal demand system with infrequency of purchase. Eur Rev Agric Econ 2010;37:501-21.

41. Scarborough $\mathrm{P}$, Nnoaham K, Clarke D, et al. Modelling the impact of a healthy diet on cardiovascular disease and cancer mortality. $J$ Epidemiol Community Health 2012;66:420-6.

42. Scarborough $\mathrm{P}$, Morgan R, Webster $\mathrm{P}$, et al. Differences in coronary heart disease, stroke and cancer mortality rates between England, Wales, Scotland and Northern Ireland: the role of diet and nutrition BMJ Open 2011;1:e000263.

43. Department of Health. National Diet and Nutrition Survey Years 1 and 2, 2008/9-2009/10. 2011.

44. Department of Health. NHS Choices. Healthy eating. 2012. http:// www.nhs.uk/livewell/healthy-eating/Pages/Healthyeating.aspx (accessed 6 Jun 2013).

45. Office for National Statistics. Death registrations by single year of age, United Kingdom 2010. 2011.

46. Williams A, Audsley E, Sandars D. Determining the environmental burdens and resource use in the production of agricultural and horticultural commodities. Defra project report IS0205. Bedford, 2006.

47. Department for the Environment Food and Rural Affairs. Survey sampling for Family Food. London, 2011. http://www.defra.gov.uk/statistics/files/ defra-stats-foodfarm-food-methodology-sampling-111213.pdf

48. Quested T, Parry A. New estimates for household food and drink waste in the UK. Banbury, 2011.

49. Andreyeva T, Chaloupka FJ, Brownell KD. Estimating the potential of taxes on sugar-sweetened beverages to reduce consumption and generate revenue. Prev Med 2011;52:413-16.

50. Lin BH, Smith TA, Lee JY, et al. Measuring weight outcomes for obesity intervention strategies: the case of a sugar-sweetened beverage tax. Econ Hum Biol 2011;9:329-41.

51. Commission on the Social Determinants of Health. Closing the gap in a generation. Geneva, 2008

52. Smed S, Jensen JD, Denver S. Socioeconomic characteristics and the effect of taxation as a health policy instrument. Food Policy 2007;32:624-39.

53. Her Majesty's Revenue and Customs. Tobacco products duty. 2012. http://www.hmrc.gov.uk/rates/tobacco-duty.htm (accessed 7 Jun 2013).

54. Price R, Thornton S, Nelson S. The Social Cost Of Carbon and the Shadow Price Of Carbon: what they are, and how to use them in economic appraisal in the UK. London, 2007. 